\section{Peer review as a business transaction}

I receive 300 requests a year to review research papers. Each takes 3-4 hours to complete, equivalent to roughly 1-2 days per week if I did them all. Should I win 'reviewer of the year' award, however, I suspect my colleagues would see my efforts as a foolish waste of time.

Reviewers are crucial to the success of prestigious and profitable journals, traditionally receiving no monetary or other recognition. As journals proliferate and scientists get ever busier, our appetite for reviewing wanes (see, for example, M. Arns Nature 515, 467; 2014). One way to revive this activity would be to consider it a business transaction - with modest remuneration of, say, US\$50 per hour (see also S. Ott and D. Hebenstreit Nature 506, 295; 2014).

Publishing in an open-access journal costs around $\$ 1,000$ $\$ 2,000$, so paying $\$ 200$ to a reviewer does not seem excessive. The authors and the journal could split the cost equally.

Prospective reviewers would be more inclined to do a speedy and thorough job. Retired scientists with extensive expertise and plenty of free time would be keen to participate. Editors would be spared the hunt for willing referees.

We could then use our reviewing fees to buy back some pleasure - I might go for a billiards table, a pinball machine or even a fancy treadmill.

Eleftherios P. Diamandis Mount Sinai Hospital and University Health Network, Toronto; and University of Toronto, Canada. ediamandis@mtsinai.on.ca

\section{Pollution: uncouple from economy boom}

The International Monetary Fund announced last year that China has overtaken the United States as the world's largest economy, accounting for $16.5 \%$ of the 2014 global gross domestic product in terms of purchasing-power parity. This achievement comes at a huge price for China.

It is well documented that China's industrial boom is causing a dangerous deterioration in air quality, as well as widespread land degradation and water and soil contamination. In 2013, 71 out of 74 Chinese cities failed to meet ambient air-quality standards (see go.nature.com/ndujl3; in Chinese).

Long-term exposure to air pollution has led to an average drop of 5 years in life expectancy for 500 million people in north China (Y. Chen et al. Proc. Natl Acad. Sci. USA 110, 12936-12941; 2013). According to the World Health Organization, respiratory disease could kill more than 3 million Chinese people every year by 2030 (V. Hughes Nature 489, S18-S20; 2012).

China must tackle its air pollution - to mitigate climate and as a priority for human health (see also J. Schmale et al. Nature 515, 335-337; 2014).

Hong-Wei Xiao China Agricultural University, Beijing, China.

A. S. Mujumdar McGill University, Quebec, Canada. Liming Che Xiamen University, Xiamen, China.

xhwcaugxy@163.com

\section{Pollution: clear blue skies over Beijing}

China's citizens coined the phrase 'APEC blue' to describe the Beijing sky during the AsiaPacific Economic Cooperation summit in November last year. This transformation from the usual heavily polluted grey was a result of tough 11-day emissionsreduction measures, enforced for the benefit of visiting dignitaries.

A week or two is not enough. China must take prompt action to extend its blue-sky days for the sake of the nation's lungs and the world's climate during the economic boom (see J. Schmale et al. Nature 515, 335-337; 2014) and call for concerted action by offending sectors (see G. Yang et al. Lancet 381, 1987-2015; 2013) .

Zhaohui Gong Ningbo University School of Medicine, Ningbo, China. zhaohui@ncri.org.cn

\section{Pollution: build on success in China}

Before the Asia-Pacific Economic Cooperation (APEC) summit in

Beijing on 5-11 November 2014, the Chinese government imposed an emergency emissionsreduction strategy to combat the city's dense smog. To deal with its environmental problems effectively, China should build on the success of this short-term intervention by establishing collaborative regional policies and compensation systems for mitigating pollution.

Production in thousands of highly polluting factories and construction sites in Beijing and its surrounding provinces was curtailed or halted for a minimum of a week before the summit. Cars with even or odd registration numbers were banned on alternate days, cutting daily traffic by some ten million vehicles.

These measures caused a sharp drop of almost $30 \%$ in the daily average concentration of particulate matter measuring up to 2.5 micrometres (PM2.5) in Beijing and nearby provinces on 1-12 November. In the city itself, PM2.5 fell to under half the concentration for the same period in 2013 (see go.nature.com/ 1s8wl1; in Chinese). Blue skies appeared during the summit and remained for a week afterwards.

Our ongoing study of urban and rural development and its environmental effects in the Bohai Rim region of China will help to assess the extent to which regulating such socio-economic changes could mitigate pollution (see go.nature.com/lo4jcz; in Chinese).

Yansui Liu, Yuheng Li, Cong Chen Beijing Normal University; and Institute of Geographic Sciences and Natural Resources Research, Chinese Academy of
Sciences, Beijing, China. liyuheng@igsnrr.ac.cn

\section{International Council for Science responds}

Your discussion of the challenges facing the International Council for Science paints a misleadingly negative picture (Nature 515, 311; 2014).

We are a non-governmental organization representing academies and research councils from 140 countries and the science community through 31 disciplinary unions, and are a leading voice for science.

The council has initiated global research projects such as the International Polar Years. Our current flagship projects are Future Earth: Research for Global Sustainability; Urban Health and Wellbeing; and Integrated Research on Disaster Risk. The biological sciences are fully integrated into our programmes (see go.nature.com/xhzhif).

The council represents science in global organizations such as the United Nations Educational, Scientific and Cultural Organization, and is the scientific and technology lead for the UN sustainable development goals programme.

The council is dedicated to the promotion of freedom and responsibility of scientists, and champions open access to data and information through its Committee on Data for Science and Technology and new World Data System. To improve links between science and policy, the council convened a meeting of governmental science advisers (www.globalscienceadvice.org), and a global network is being established.

Details of these activities and the external review report commissioned by the council can be found at www.icsu.org.

Gordon McBean ${ }^{\star}$ International Council for Science, Paris. gmcbean@uwo.ca ${ }^{*}$ On behalf of 15 correspondents (see go.nature.com/v591un for full list). 